Original Research Article

\title{
Economic burden of diabetes mellitus in western India: a hospital based study
}

\author{
Arpit Prajapati $^{1}$, Nitin Kothari ${ }^{2}$, Barna Ganguly ${ }^{3}$
}

\begin{abstract}
${ }^{1}$ Manager, Clinical
Development, Dr. Reddy's

Laboratory Ltd, Hyderabad,

Telangana, India

${ }^{2}$ Assistant Professor,

Department of Pharmacology,

Pacific Medical College and

Hospital, Udaipur, Rajasthan,

India

${ }^{3}$ Department of Pharmacology,

Pramukh Swami Medical

College, Karamsad, Anand,

Gujarat, India
\end{abstract}

Received: 09 September 2016

Accepted: 08 October 2016

\section{*Correspondence to: \\ Dr. Nitin Kothari, \\ Email: nknitinkothari@ \\ gmail.com}

Copyright: (C) the author(s), publisher and licensee Medip Academy. This is an openaccess article distributed under the terms of the Creative Commons Attribution NonCommercial License, which permits unrestricted noncommercial use, distribution, and reproduction in any medium, provided the original work is properly cited.

\begin{abstract}
Background: Descriptive cost of illness study can provide an overall picture of diabetes in monetary terms in developing country, which may serve as a vital source of information for health care organizations and planning bodies to plan and prioritize local health policies and schemes. The aim was to explore cost description of diabetes in a tertiary care hospital in Anand district of Gujarat, India.

Methods: This was an observational study with one year follow up. Ethical approval was taken from IEC. Patients were recruited and were divided into three categories according to duration of diabetes; newly diagnosed cases as category I, diabetes since last 5 year as category II and since last 10 years as category III. All these patients were followed up with 4 visits. Cost was calculated into three components; direct medical, direct non-medical and indirect cost. Descriptive and regression analysis was done using SPSS version 17.0.

Results: Total 90 patients were analyzed after 12 patients were lost to follow up, 30 in each category. Mean total cost was found to be 12391.84 INR. Contributions from direct medical cost, direct non-medical cost and indirect cost were $74 \%, 2 \%$ and $24 \%$ respectively. Maximum cost incurred was due to medicine cost $(44.14 \%)$ followed by complication cost $(43.34 \%)$.

Conclusions: Heavy economic burden highlights the urgent need for the health care organizations to plan and prioritize policies and accordingly in prevention and management of diabetes and its complications.
\end{abstract}

Keywords: Cost of illness, Direct cost, Indirect cost

\section{INTRODUCTION}

The health care system is clearly in state of rapid revolution. Choices and decisions abound in today's health care environment. The central problem in economics is to find a socially acceptable solution to people's unlimited demands and society's limited ability to respond to these demands with production of goods and services. ${ }^{1}$ Traditional approaches to health care decisions will no longer suffice; therefore, new tools will be needed. ${ }^{2}$ With increasing health care costs, limits on health care resources, changing reimbursement patterns, and debate over the effectiveness of health care treatments, many of these choices are difficult to embrace. $^{3}$ Medical, ethical and societal concerns about costs, access and quality of care are causing healthcare practitioners to consider a more comprehensive model for medical decision making. These trends led to the evolution of Pharmacoeconomics. ${ }^{4}$ Cost of Illness (COI) studies are often cited as an important element in the choices made regarding disease care and management. At the core, COI studies represent a descriptive pharmacoeconomics method. The estimates provide information that describes the resources used and potential resources lost that are related to a disease. ${ }^{3}$

In the $21^{\text {st }}$ century we stand amidst a pandemic of diabetes. Diabetes, with a global prevalence of $6.6 \%$, 
affects about 7 billion people around the world. ${ }^{5-8}$ Diabetes, due to its deadly complications, accounts for around 4 million deaths per year, similar in magnitude to HIV/AIDS. ${ }^{9,10}$ Around $80 \%$ of the world's diabetic population lives in the developing countries. India, with a diabetic population of around 50.8 million tops the list of all countries affected by diabetes and is rightly rewarded the title of "Diabetic Capital" of the world. India will continue to occupy this position till 2030 with an estimate of 87 million people with diabetes. ${ }^{5-8}$ The prevalence of diabetes varies from $9 \%$ to $16.6 \%$ in different regions, with the southern region of India having higher prevalence rates than other parts of India. ${ }^{11} \mathrm{~A}$ national survey found that the prevalence of diabetes in rural areas was $3.1 \% .^{12}$ The prevalence of diabetes has been steadily increasing in urban areas. ${ }^{11}$ There is evidence to suggest that prevalence of diabetes is also increasing in rural areas. $^{13}$

Despite such an alarming prediction that the prevalence of diabetes in India is expected to increase, there have been few studies of the status and economic burden of diabetes in India. Health resources in India and other developing countries are very limited with only $5 \%$ of Gross Domestic Product (GDP), (US \$, 23 per capita) being spent on healthcare. ${ }^{14}$ The majority of healthcare expenditure was private (4\% of GDP) with only 0.9 per cent of GDP spent on public health care. ${ }^{15}$ The per capita expenditure on health care in India is only 6.4 per cent of the average world spending, while India accounts for 23.5 per cent of the world's disability adjusted life years (DALYs) lost due to diabetes. The estimated national expenditures on diabetes will be at least 2.8 billion US \$ in 2010 , and at least 4.8 billion US $\$$ in $2030 .^{10}$ Though not distributed evenly across countries, age and gender, some studies have documented that the total cost of diabetes care in terms of cost is higher. ${ }^{16}$

This descriptive cost of illness study can provide an overall picture of diabetes in monetary terms in developing country, which may serve as a vital source of information for health care organizations and planning bodies to plan and prioritize local health policies and schemes. This study was designed with objective to explore cost description of diabetes mellitus.

\section{METHODS}

This was an observational study spreaded over a period of 18 months from February 2010 to July 2011, conducted in Shree Krishna Hospital, a tertiary care teaching rural hospital attached to Pramukh Swami Medical College, Karamsad, Anand, Gujarat, India. Ethical approval was taken from the Institutional Human Research Ethics Committee prior to study. The patients visiting the diabetic outpatient clinic, diagnosed as diabetes mellitus type 2 were included in the study. The patients with/without complication were included in the first visit were included. Pregnant patients presenting with diabetes were excluded.
Patients attending to diabetic outpatient clinic were randomly selected and recruited in the study and divided into 3 categories according to duration of diabetes into three categories: 1) newly diagnosed cases (within three months of diagnosis), 2) diagnosed since last 5 years and 3) diagnosed since last 10 years. All the patients participating in the study were explained early about the purpose and nature of the study in the language they can understand and written informed consent was taken before including them in the study. Patients were interviewed for approximately 30 minutes and necessary information regarding disease and therapy were collected as per case record form. All these patients were followed up for next 12 months. Minimum four visits were expected. At these visits patients were asked about defined parameters about hospitalization in between or any complication of the disease itself and its treatment taken. The patients considered as lost to follow up if the number of follow up visits were less than four during one year follow up period.

The cost was differentiated into three components:

1. Direct medical cost

2. Direct non-medical cost

3. Indirect cost

Direct medical cost includes a) consulting cost - regular and special consulting charges, b) investigation cost charges of investigation done to see control over diabetes and includes charges of Randomized Blood Sugar (RBS), Fasting Blood Sugar (FBS), Post prandial blood sugar (PP2BS), Urine glucose and HbA1c, c) medicines cost Oral Hypoglycemic Agent (OHA) and insulin cost d) home monitoring cost - cost of glucometer and its strips e) alternative medicine cost - cost of complementary and alternative medicines or some other homemade remedies, f) complication cost - includes investigation cost charge of investigation done to screen complication of DM which includes urine albumin and serum creatinine for nephropathy, fundus examination of retina for retinopathy and nerve conduction velocity test for neuropathy, medicine cost - cost of medicines prescribed to them for various complication during follow up period and hospitalization cost. Direct non-medical cost includes cost of special food articles used by patients to control glucose level e.g. sugar free, transport cost - cost of transport from patients' home to the hospital along with their care giver. Indirect cost includes lost wages and lost household production of patients and care giver due to regular check up in the hospital and due to hospitalization during one year period.

\section{Sources of different cost}

Cost of special food and transport was obtained from the patient in the interview and it was self-explaining. Home monitoring cost and cost of alternative medicines were 
obtained from the patients and were also self-explaining. Charges of consultation, various investigations and hospitalization were obtained from hospital record section. Cost of various medicines and cost of syringes, needles and cotton swab were obtained from hospital pharmacy department. Lost wages were calculated by dividing their monthly income by their days lost due to illness and then total them for the whole year (human capital approach) . Lost household productions were calculated by opportunity cost of hiring a replacement from the labor market and total them for the whole year. All these costs were calculated per month and then according to change in the prescription of medicines in follow up visits, cost was recalculated from that follow up to the next follow up period. Finally, cost of the whole year was obtained by summation of twelve months cost.

\section{Statistical analysis}

Analysis was done using software SPSS version 17.0. Descriptive statistics in terms of frequency counts and percentages were used for discrete variables such as socio-demographic variables. Mean and standard deviations were calculated for all the continuous variables that is, certain socio-demographic variables and various costs variables. Pearson Chi-Square test was applied to compare frequency among three categories of diabetes. Oneway ANOVA test was applied to compare mean of different cost among three category of diabetes. Transformed linear regression model was computed to determine the variables significantly associated with increased cost. Result was considered as significant if $p$ value was less than 0.05 .

\section{RESULTS}

Total 102 patients of three categories were recruited into the study. Out of these, 32 belonged to category I, 35 belonged to category II and 35 belonged to category III. At the end of the study, 90 patients completed the study with four follow up in their one year duration period. Total 12 patients were lost to follow up, 2 in category I and 5 in each category II and III. So finally analysis was done on those 90 patients with complete follow up.

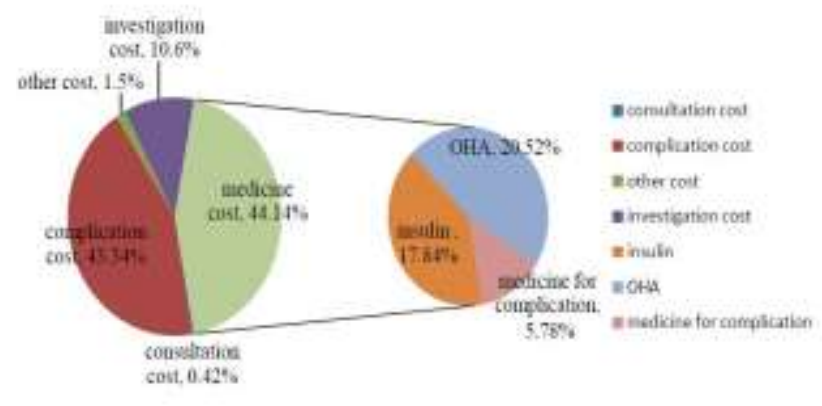

Figure 1: Different component of direct medical cost in diabetic patients.

\section{Sample description}

Mean age of the patients was 54.91 years and ranging from 20 to 77 years. Mean duration of diabetes of the patients was 7.18 years and ranged from 1 month to 32 years. Majorities of the patients were belonged to middle age group between 40-65 years. Most of them were literate $(96 \%)$ and $86 \%$ of them belonging to lower middle socio-economic class and above. Only 37 $(41.11 \%)$ patients were coming with their care givers and $14(15.55 \%)$ were visiting specialty OPD. $64(71.11 \%)$ patients had co-morbidity or developed co-morbidity during follow up period.43 (47.73\%) patients had complication or developed it and 27 (30\%) patients needed hospitalization during follow up period. Other details of socio-demographic data are given in table no. 1. Mean days of hospitalization was calculated to be 5.77 among 27 patients who needs hospitalization. Total numbers and days of hospitalization among them were 43 and 156 respectively in one year follow up period.

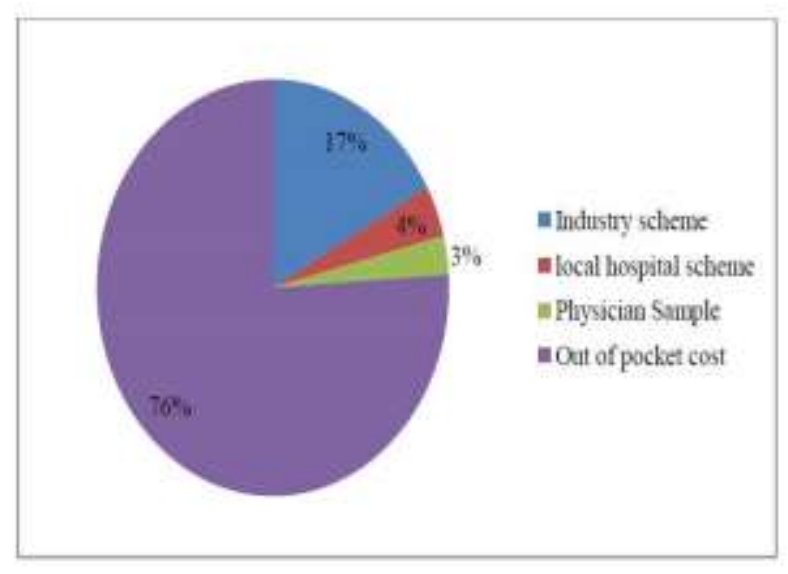

Figure 2: Source of funding in all diabetic patients.

\section{Cost of different component of diabetes}

Mean of total diabetic cost among all patients was found to be 12391.84 INR. Direct medical cost contributed to $74 \%, 2 \%$ by direct non-medical cost and $24 \%$ by indirect cost of the total diabetic cost. Mean cost of diabetes among different categories are given in table no. 2 with $\mathrm{p}$ value among them.

Among the direct medical cost, maximum expenditure was due to medicine cost $(44.14 \%)$ and complication cost $(43.34 \%)$. Investigation for diabetes contributed to $10.60 \%$ of total direct medical cost. Details regarding direct medical cost are given in figure no. 1. Others diabetic expenditure includes cost of goods (syringes, needles and cotton swabs), home monitoring cost and alternative medicine cost. In case of direct non-medical cost, mean transport cost was found to be 221.64 INR and mean cost for special food was 10 INR. 
Mean of days lost by patients in this study was found to be $7.89,6.16$ days due to regular check-up and 1.73 days due to hospitalization. Same way lost days of care giver was given in table no. 3. Total indirect cost was found to be 2928.32 INR. Difference among the three categories was found to be non-significant.

Table 1: Patients' characteristics with three different categories of diabetes.

\begin{tabular}{|c|c|c|c|c|}
\hline Parameter & Category I (\%) & Category II (\%) & Category III (\%) & Total \\
\hline $\mathbf{N}$ & $30(33.33)$ & $30(33.33)$ & $30(33.33)$ & 90 \\
\hline \multicolumn{5}{|l|}{ Age (Years) } \\
\hline $19-39$ & $7(58.33)$ & $5(41.66)$ & $0(0)$ & 12 \\
\hline $40-65$ & $21(32.81)$ & $23(35.93)$ & $20(31.25)$ & 64 \\
\hline$>65$ & $2(14.28)$ & $2(14.28)$ & $10(71.42)$ & 14 \\
\hline \multicolumn{5}{|l|}{ Sex } \\
\hline Male & $18(36.73)$ & $14(28.57)$ & $17(34.69)$ & 49 \\
\hline Female & $12(29.26)$ & $16(39.02)$ & $13(31.70)$ & 41 \\
\hline \multicolumn{5}{|l|}{ Residency } \\
\hline Urban & $15(34.07)$ & $16(36.36)$ & $13(29.54)$ & 44 \\
\hline Rural & $15(32.60)$ & $14(30.43)$ & $17(36.95)$ & 46 \\
\hline \multicolumn{5}{|l|}{ Education } \\
\hline Illiterate & $3(75)$ & $1(25)$ & $0(0)$ & 4 \\
\hline Primary & $2(11.76)$ & $9(52.94)$ & $6(35.29)$ & 17 \\
\hline Secondary & $3(21.42)$ & $6(42.85)$ & $5(35.71)$ & 14 \\
\hline Higher secondary & $10(50)$ & $3(5)$ & $7(35)$ & 20 \\
\hline Graduate & $10(35.71)$ & $9(32.14)$ & $9(32.14)$ & 28 \\
\hline Post graduate & $2(28.57)$ & $2(28.57)$ & $3(42.85)$ & 7 \\
\hline \multicolumn{5}{|l|}{ Occupation } \\
\hline Unemployed & $12(30.76)$ & $15(38.46)$ & $12(30.76)$ & 39 \\
\hline Unskilled & $0(0)$ & $1(100)$ & $0(0)$ & 1 \\
\hline Semi-skilled & $2(25)$ & $2(25)$ & $4(50)$ & 8 \\
\hline Skilled & $10(35.71)$ & $7(25)$ & $11(39.28)$ & 28 \\
\hline Semi professional & $6(42.85)$ & $5(35.71)$ & $3(21.42)$ & 14 \\
\hline \multicolumn{5}{|l|}{ SES } \\
\hline High & $3(21.42)$ & $4(28.57)$ & $7(50)$ & 14 \\
\hline Upper middle & $9(33.33)$ & $10(37.03)$ & $8(29.62)$ & 27 \\
\hline Lower middle & $12(34.28)$ & $11(31.42)$ & $12(34.28)$ & 35 \\
\hline Poor & $6(42.85)$ & $5(35.71)$ & $3(21.42)$ & 14 \\
\hline Special food & $1(14.28)$ & $3(42.85)$ & $3(42.85)$ & 7 \\
\hline \multicolumn{5}{|l|}{ Transport } \\
\hline Walk & $1(20)$ & $0(0)$ & $4(80)$ & 5 \\
\hline Auto & $8(25.80)$ & $11(35.48)$ & $12(38.70)$ & 31 \\
\hline Bus & $9(40.90)$ & 8 (36.36) & $5(22.72)$ & 22 \\
\hline Private vehicle & $12(37.5)$ & $11(34.37)$ & $9(28.12)$ & 32 \\
\hline \multicolumn{5}{|l|}{ Transport with } \\
\hline Alone & $20(37.73)$ & $17(32.07)$ & $16(30.18)$ & 53 \\
\hline With Care Giver & $10(27.02)$ & $13(35.13)$ & $14(37.83)$ & 37 \\
\hline \multicolumn{5}{|l|}{ OPD } \\
\hline Regular & $29(38.15)$ & $25(32.89)$ & $22(28.94)$ & 76 \\
\hline With Special & $1(7.14)$ & $5(35.71)$ & $6(42.85)$ & 14 \\
\hline $\begin{array}{l}\text { Syringe, needle and } \\
\text { cotton }\end{array}$ & $3(15)$ & $7(35)$ & $10(50)$ & 20 \\
\hline Home monitoring & $2(12.5)$ & $4(25)$ & $10(62.5)$ & 16 \\
\hline Alternative medicines & $9(33.33)$ & $10(37.03)$ & $10(37.03)$ & 27 \\
\hline \multicolumn{5}{|l|}{ Therapy } \\
\hline OHA & $27(38.57)$ & $23(32.85)$ & $20(28.57)$ & 70 \\
\hline
\end{tabular}




\begin{tabular}{|lllll|}
\hline With insulin & $3(15)$ & $7(35)$ & $10(50)$ & 20 \\
\hline Co-morbidities & $14(21.9)$ & $21(32.8)$ & $29(45.3)$ & 64 \\
\hline Complications & $9(20.9)$ & $18(41.9)$ & $16(37.2)$ & 43 \\
\hline No. of Hospitalization & & & $3(23.1)$ & 13 \\
\hline Once & $3(23.1)$ & $7(53.8)$ & $6(50)$ & 12 \\
\hline Twice & $3(25)$ & $3(25)$ & $0(0)$ & 2 \\
\hline Thrice & $1(50)$ & $1(50)$ & & \\
\hline
\end{tabular}

\section{Analysis of complication and hospitalization}

Out of total 90 diabetic patients, 43 (47.78\%) patients developed one or more diabetic complications in one year follow up period. Mean cost among patient with complication was 18416.98 INR which were 6879.49 INR in patients without complication. This difference was found to be significant with $\mathrm{p}$ value of 0.001 . Among total study group, 27 (30\%) patients need hospitalization during their one year follow up period. Mean cost was again found to be significantly higher in patient with hospitalization than who don't need it (23953.22 INR vs.
7436.98 INR) with $p$ value of 0.001. Comparing patients on OHA therapy and insulin therapy, significant numbers of the patients developed complication in insulin group, with $\mathrm{p}$ value of 0.001 (16 out of 20 patients on insulin had complication as compared to 27 patients out of 70 on OHA therapy). Same is true for hospitalization. 12 patient need hospitalization in patients who were one insulin therapy and 15 patients need hospitalization in patients on OHA therapy ( $\mathrm{p}$ value -0.001 ). Mean diabetic cost was found to be much higher in patients who were on insulin than those who were on OHA therapy (9949.40 INR in insulin group vs. 2145.71 INR in OHA group, p value $0.0001)$.

Table 2: Cost of different component of diabetes and their comparison in Indian rupees (INR).

\begin{tabular}{|c|c|c|c|c|c|c|}
\hline Cost (INR) & & $\begin{array}{l}\text { Category I } \\
(n=30)\end{array}$ & $\begin{array}{l}\text { Category II } \\
(\mathbf{n}=\mathbf{3 0})\end{array}$ & $\begin{array}{l}\text { Category III } \\
(\mathbf{n}=\mathbf{3 0})\end{array}$ & Total $(n=90)$ & p value \\
\hline \multirow{2}{*}{$\begin{array}{l}\text { Direct } \\
\text { Medical }\end{array}$} & Mean & 8053.27 & 9464.03 & 10178.33 & 9231.88 & \multirow{2}{*}{0.72} \\
\hline & SD & 12565.21 & 7465.11 & 10493.63 & 10308.88 & \\
\hline \multirow{2}{*}{$\begin{array}{l}\text { Direct Non- } \\
\text { medical }\end{array}$} & Mean & 251 & 229.6 & 214.33 & 231.64 & \multirow{2}{*}{0.78} \\
\hline & SD & 224.57 & 167.85 & 219.79 & 203.92 & \\
\hline \multirow{2}{*}{ Indirect } & Mean & 3061.67 & 3181.10 & 2542.20 & 2928.32 & \multirow{2}{*}{0.76} \\
\hline & SD & 3360.64 & 4121.47 & 3070.05 & 3516.23 & \\
\hline \multirow{2}{*}{ Total } & Mean & 11365.93 & 12874.73 & 12934.87 & 12391.84 & \multirow{2}{*}{0.86} \\
\hline & SD & 15226.78 & 10063.98 & 12571.61 & 12672.08 & \\
\hline
\end{tabular}

Out of pocket cost (OOPC) or self-financing remains major source for funding in diabetic expenditure in this study $(76 \%)$. Other source of funding was given in figure no. $2.5 \%$ of the total family income $(21 \%$ of per capita income) was spent by patient on diabetes in one year.

\section{Regression analysis}

Linear regression model with direct cost as dependent variable showed that visiting specialty OPD $(0.30,0.003)$ ( $\beta$ coefficient, $p$-value) significantly increased cost for diabetes care, while higher income status $(0.285,0.031)$ and presence of care giver $(0.214,0.043)$ were the significant variable associated with indirect cost.

\section{DISCUSSION}

Health economics, it has been said, is not all about money alone but also about humanitarian considerations of the quality of life of millions affected with the disease. Since diabetes is a chronic disease associated with comorbidities and complications, it has a substantial impact on the cost of care. In addition to this, in countries like India and other developing countries lack of access to health care services, lack of national welfare schemes and health insurance coverage for diabetes make the treatment unaffordable resulting in late diagnosis and increased cost in treatment of diabetes and early onset of complications as compared to developed nations. 
Table 3: Different component of indirect cost among diabetic patients.

\begin{tabular}{|ll|}
\hline $\begin{array}{l}\text { Mean days lost by patient because } \\
\text { of regular follow up }\end{array}$ & $\mathbf{6 . 1 6}$ \\
\hline $\begin{array}{l}\text { Mean days lost by patient because of } \\
\text { hospitalization }\end{array}$ & 1.73 \\
\hline $\begin{array}{l}\text { Mean days lost by care giver because } \\
\text { of regular follow up }\end{array}$ & 2.62 \\
\hline $\begin{array}{l}\text { Mean days lost by care giver because } \\
\text { of hospitalization }\end{array}$ & 2.19 \\
\hline Mean income/month of patients & 8366.67 (INR) \\
\hline Mean income/month of care gives & 11988.90 (INR) \\
\hline Mean lost wage of patients & $\begin{array}{l}1519.99 \text { INR } \\
(51.90 \%)\end{array}$ \\
\hline $\begin{array}{l}\text { Mean lost household production of } \\
\text { caregivers }\end{array}$ & $\begin{array}{l}296.67 \text { INR } \\
(10.13 \%)\end{array}$ \\
\hline Mean lost wage of patients & $\begin{array}{l}950 \mathrm{INR} \\
(32.44 \%)\end{array}$ \\
\hline $\begin{array}{l}\text { Mean lost household production of } \\
\text { caregivers }\end{array}$ & $\begin{array}{l}161.67 \text { INR } \\
(5.52 \%)\end{array}$ \\
\hline Mean total indirect cost & 2928.32 INR \\
\hline
\end{tabular}

According to different perspective, cost of diabetes studies can be categorized by three study designs. First include designs based on diagnostic category data (ICD codes) from general population surveys, second would be responses from persons with diabetes, and third, cost projections from previous studies. Cost estimates in this study were based on the response of individual and "bottom-up" approaches, which are particularly helpful in evaluating and comparing economic burden of different disorders. ${ }^{17,18}$

Difference in perspectives in conducting cost of illness study might get different result. Difference in setting of the study is another major factor that can contributes to difference in the cost. Study conducted in population setting includes patient at large scale and usually cross sectional survey based study. Compared to that, study based on hospital set up are more difficult and time consuming especially with long follow up studies. Although cost estimations were primarily based on a survey of patients, to increase reliability and comprehensiveness of data, information was also obtained from other sources such as relatives, medical records, and hospital sources. Costs were assessed four times after recruiting the patient and added up to yield average figures over one year period to meet previous recommendations for a minimally acceptable duration of three to six months for calculating treatment costs. ${ }^{19}$

Advantage of surveying method can be seen in a review by Songer et al. $^{20}$ This method gives more precise estimates of the costs of the diabetes because individual costs and utilization patterns are observed directly, rather than estimated from ICD categories. Second advantage of this method is, if a representative sample of the population is used, data based on the reports of people with diabetes are much more likely to reflect the experience of the diabetes population than are data based on diagnostic categories. The disadvantage of this method is that it is an expensive process. Furthermore, many of the national estimates related to diabetes are based on the responses of a limited number of persons.

In this study, patients were categorized into 3 groups according to duration of DM. Although there is a difference in diabetic cost among three categories, but $\mathrm{p}$ value among these groups is not significant. None of the previously done studies showed the difference in this way. This finding can be explained by two reasons. First is although these categories were based on duration of diabetes, the actual development of diabetes as a disease may be much before the diagnosis so rate of complication and hospitalization will be varied. Second possible reason is significant correlation of diabetic cost among different categories with SES and family income of the patients which was seen in regression analysis.

Mean of direct medical cost was found to be 9231.88 INR ( $74 \%$ of the total diabetic cost). Mean of total direct non-medical cost was found to be 231.64 INR (2\%). Thus mean of total direct cost of the study group was found to be 9463 INR (76\%). Results from the other studies were also comparable; mean total direct medical cost was estimated to be 4966.42 INR $(71.25 \%)$ by Grover $\mathrm{S}$ et al (calculated cost of six months, in our study it was 4732 INR). ${ }^{21}$ Direct medical cost in the other study was varying greatly, from 7158 INR $(35 \%)$ by Kapur A et al to 20500 INR in Bhaskaran VP et al. ${ }^{22,23}$ Compared with other countries, mean direct medical cost of diabetes in Iran was found to be $152.3 \$, 79 \%$ of total diabetic cost (Esteghamati A et al in Tehran, Iran) and 94.71 US \$ in Thailand. ${ }^{24,25}$

In our study, mean direct medical cost was 188 US \$. In other studies, mean direct medical cost varied from 14 US \$ (Khowaja LA et al in Pakistan) to 703 US \$ (Barcelo et al in Latin America and Caribbean). ${ }^{26,27}$

Maximum contribution in direct medical cost was made by medicines (44.14\%), followed by cost of complications (43.34\%). Medicine cost is a major contributor in any cost of illness study. Cost of hospitalization also included in complication cost which was a major component of it. Investigation cost contributed to $10.60 \%$. Consulting cost in this study was only $0.42 \%$, which can be explained on the basis of free consultation was there in this set up for regular consultation. $1.5 \%$ of the total diabetic cost was contributed by cost of alternative medicines, cost of home monitoring and cost of syringes, needles and cotton.

There was extensive variation in the cost of different component of direct medical cost of diabetes. $43.34 \%$ of total diabetic cost was contributed by complication cost, which was similar to Riewpaiboon A et al in Thailand. ${ }^{25}$ This suggests that diabetic complications are major 
determinant of cost of diabetes. Mean of total diabetic cost among patients who need hospitalization was found to be 17611.78 INR in this study. This finding was also comparable with previous studies. In study by Sachidananda A et al mean cost was found to be 12781 INR and 13200 INR in study by Bjork $\mathrm{S}$ et al in India. ${ }^{28,29}$ If we compare by adding inflation rate both studies were comparable.

In the treatment guideline of type $2 \mathrm{DM}, \mathrm{OHA}$ is the first line medicines in most of the cases. Indication for insulin is very limited. In this study, it was seen that patients were on insulin only when they have treatment failure to OHA or in case of severe uncontrolled diabetes at the time of hospital admission. Cost of insulin was much higher as compared to OHA medicines and it also adds cost of other goods like syringes, needles and cotton swab. Mean of total diabetic cost in patients who were on insulin therapy was found to be 9949.40 INR and 2145.71 INR in patients who are on OHA therapy.

Similar findings were seen in two national studies, by Kumar A et al and by Bhaskaran VP et al. ${ }^{23,30}$ This finding suggests that insulin therapy is very costlier as compared to OHA therapy.

Mean of total indirect cost was calculated to be 2928.32 INR, $24 \%$ of the total diabetic cost. In previous studies, it was found to be 2086.74 INR $(28.74 \%)$ over six months (in our study, mean of total indirect cost for six months will be approximately 1466.32 INR) in Grover S et al and 1722 INR (13\%) in Rayappa PH et al. ${ }^{21,31}$

Indirect cost includes the loss of resources due to morbidity and mortality, which inherently places a monetary value on the values of life. It mainly includes cost of absenteeism; cost of disability payment and cost of premature death. ${ }^{32}$ In our study for the calculation of indirect cost, only cost of absenteeism was included by calculating lost wages and lost household production of the patients and the care-givers.

Indirect costs were calculated using the "human capital" approach, as this method was found to be more accurate than other methods like "willingness to pay" approach which would overestimate the indirect cost. ${ }^{33}$ Although future mortality costs could not be assessed because of difficulties in obtaining requisite information and only morbidity cost was assessed in this study.

Source of funding for the cost of diabetes is very important. In our study we had found that maximum funding for the diabetic cost was in the form of out of pocket cost (OOPC) or self-financing. OOPC had covered $76 \%$ of the total diabetic cost. Next major component was covered by industry scheme of the hospital. It had covered $17 \%$ of the total cost. Remaining $7 \%$ of the cost was taken care by local scheme of the hospital $(4 \%)$ and free medicines in form of physician samples to some lower socio-economic class patients
(3\%). Very few studies had categories the source of funding. Similar type of findings was seen by Bhaskaran VP et al. ${ }^{23}$ This finding suggests that up till now majority of the Indian patients were using OOPC for their medical expenditure and very less of them depends on medical insurance type of things as seen in developed countries.

As diabetes is a chronic disease and its burden remain throughout life on patient as well as on the family member in the form of either direct or indirect. Percentage of income spent on DM by patients had been calculated in this study to know the exact burden at the individual and at the family level. It was seen that $5.07 \%$ of the total family income was spent for the treatment of DM. It remained same among all the categories of DM. This suggests high amount of burden of patients as well as on family members due to diabetes in our country and other nations where there is lack of insurance coverage for the individual.

Limited sample size was main limitation of this study. This study was done without control, so attributable risk factor can't be calculated which makes cost of comorbidity and complication more precise. Present cost of illness study ignored the intangible cost such as pain and suffering from the disease and lack of sensitivity analysis.

Present study has given basic information regarding burden of diabetes among the patients of this hospital and this locality. Total diabetic cost was found to be 12391 INR per year per patient which is almost similar to other part of the country. Patient needs to spend $5 \%$ of his family income for the effective care of diabetes. As diabetes is a chronic disease and complication of it is bound to occur in future with advance progression of the disease, cost of diabetic care is going to be much higher in patients in future. So, there is a need of more explored study in this area.

\section{CONCLUSION}

Action taken early in the course of diabetes is more beneficial in terms of quality of life and is more cost effective, especially if it can prevent hospitalization. Proper management requires investment in awareness, education and better care. Providing health care to prevent and treat diabetic complications requires resources.

Keeping the future diabetes explosion in mind, this heavy economic burden highlights the urgent need for the health care organizations and planning bodies to plan and prioritize local health policies and schemes accordingly in prevention and management of diabetes and its complications.

\section{ACKNOWLEDGEMENT}

Authors would like to acknowledge Dr. S. Biswas, faculty of Institute of Rural Management Anand (IRMA), 
India and Ms. Jayshree Ganjiwala, Biostatistician, Shree Krishna Hospital, Karamsad, India.

Funding: No funding sources

Conflict of interest: None declared

Ethical approval: The study was approved by the Institutional Ethics Committee

\section{REFERENCES}

1. Davey PG, Malik M, Dodd T, MacDonald $T$. Pharmacoeconomics and Drug Prescribing. In: Speight TM, Holford NHG, editors. Avery's drug treatment. 4th ed. Auckland: Adis International; 1997. p. 393-422.

2. Townsend RH. Post-marketing drug research and development. Drug Intell Clin Pharm. 1997;21:134-6.

3. Songer TJ, Ettaro L. Studies on the Cost of Diabetes. Prepared for Division of Diabetes Translation Centers for Disease Control and Prevention Atlanta, GA. 1998 Jun.

4. World Health Organization. Health Economics, drug and health sector reform. WHO task force on health economics. 1996.

5. Sicree BR, Shaw J, Zimmet P. The Global Burden Diabetes and Impaired Glucose Tolerance: IDF Diabetes Atlas. 4th edition [Online] 2009 [cited 2011 Nov 7]. Available from: URL: http://www.idf.org/diabetesatlas/downloads/backgrou ndpapers.

6. Gor A, Kothari N, Shah P, Gaur K. Use of complementary and alternative medicine (CAM) in patients with essential hypertension and diabetes mellitus attending a tertiary care teaching hospital. Int J Med Sci Den Health. 2015;1:50-7.

7. Upadhyay TR, Kothari N, Shah Hitesh . Association Between Serum B12 and Serum Homocysteine Levels in Diabetic Patients on Metformin. Journal of Clinical and Diagnostic Research. 2016;10:BC01-4.

8. Agrawal NK, Singh R, Kothari N, Bala S, Gupta U. Evaluation of the Effect of Perindopril and its Combination with Oral Anti-Diabetic Drugs on Blood Sugar Levels in Diabetic Wistar Rats. Asian Journal of Biomedical and Pharmaceutical Sciences. 2014;4:44-9.

9. Agrawal NK, Sindhu S, Kothari N, Chandra S, Garima G, Gupta U. Antidyslipidemic activity of acacia tortilis seed extract in alloxan-induced diabetic rats. Int J Basic Clin Pharmacol. 2016;5:1389-96.

10. Zhang P, Zhang X, Brown JB, Vistisen D, Sicree RA, Shaw J, et al. Economic impact of Diabetes: IDF Diabetes Atlas. 4th edition [Online]. 2009 [cited 2011 Nov 7]. Available from: URL: http://www.idf.org/diabetesatlas/downloads/backgrou ndpapers.

11. Ramachandran A, Snehlata C, Kapur A, Vijay V, Mohan V, Das AK, et al. Diabetes Epidemiology Study Group in India (DESI): High prevalence of diabetes and impaired glucose tolerance in India:
National Urban Diabetes Survey. Diabetologia. 2001;44:1094-101.

12. World Health Organization. Demographic trends. In: Health Situation in the South East Asian Region 1998-2000. Regional Office for South East Asia, New Delhi, 2002;17-30.

13. Ramachandran A, Snehalatha C, Baskar ADS, Mary S, Kumar CK, Selvam S, et al. Temporal changes in prevalence of diabetes and impaired glucose tolerance associated with lifestyle transition occurring in the rural population in India. Diabetologia. 2004;47:860-5.

14. Peters DH, Yazbeck SA, Sharma RR, Ramana GNV, Pritchett LH, Wagstaff A. A better health systems for India's poor: Findings analysis and options. World Bank; 2002. Available from URL: http://www.worldbank.org/publications/pdfs/15029o verview.pdf.

15. Kapur A. Economic analysis of diabetes care. Indian J Med Res. 2007;125(3):473-82.

16. Barcelo A, Aedo C, Rajpathak S, Robles S. The cost of diabetes in Latin America and the Carribbean. Bull World Health Organ. 2003;81:19-28.

17. Shah A, Jenkins R. Mental health economic studies from developing countries reviewed in the context of those from developed countries. Acta Psychiatr Scand. 2000;101:87-103.

18. Rice DP, Miller LS. Health economics and cost implications of anxiety and other mental disorders in the United States. Br J Psychiatry. 1998;34:4-9.

19. McCrone P, Weich S. Mental health care costs: paucity of measurements. In: Thornicroft G, Tansella M, eds. Mental health outcome. London: Springer, 1996:131-42.

20. Songer TJ. The economics of diabetes care:USA. In: Alberti KGMM, Zimmet P, DeFronzo RA, eds. International textbook of diabetes mellitus. 2nd ed. Chichester: Wiley, 1997.

21. Grover S, Avasthi A, Bhansali A, Chakrabarti S, Kulhara P. Cost of ambulatory care of diabetes mellitus: a study from north India. Postgrad Med J. 2005;81:391-5.

22. Kapur A. Economic analysis of diabetes care. Indian J Med Res. 2007;125(3):473-82.

23. Bhaskaran VP, Rau NR, Satyashankar, Acharya RR, Chinnappa S, Metgud, et al. A Study of the Direct Costs Incurred by Type-2 Diabetes Mellitus Patients for their Treatment at a Large Tertiary-Care Hospital in Karnataka, India. J Acad Hosp Adm. 2003;15(2):7-12.

24. Esteghamati A, Khalilzadeh O, Anvari M, Meysamie A, Abbasi M, Forouzanfar M, et al. The economic costs of diabetes: a population-based study in Tehran, Iran. Diabetologia. 2009;52:1520-7.

25. Riewpaiboon A, Chatterjee S, Piyauthakit P. Cost analysis for efficient management: diabetes treatment at a public district hospital in Thailand. Int $\mathbf{J}$ Pharm Pract. 2011;19:342-9.

26. Khowaja LA, Khuwaja AK, Cosgrove P. Cost of diabetes care in out-patient clinics of Karachi, 
Pakistan. BMC Health Services Research. 2007;7(189):1-8.

27. Barcelo A, Aedo C, Rajpathak S, Robles S. The cost of diabetes in Latin America and the Carribbean. Bull World Health Organ. 2003;81:19-28.

28. Sachidananda A, Lin JTG, Usha A. Health care cost incurred by patients of diabetes mellitus in a tertiary care hospital setting in coastal karnataka district. Journal of Global Pharma Technology. 2010;2(6):812.

29. Bjork S, Kapur A, Sylvest C, Kumar D, Nair J, Kelkar S. Diabetes Care Organization and Economics - the Economic Burden of Diabetes in India: results from a National Survey. In: Forum 9; 2005 Sep 1216; Mumbai, India.

30. Kumar A, Nagpal J, Bhartia A. Direct Cost of Ambulatory Care of Type 2 Diabetes in the Middle and High Income Group Populace of Delhi: The DEDICOM Survey. J Assoc Physicians India. 2008;56:667-74.

31. Rayappa PH, Raju KNM, Kapur A, Bjork S, Sylvest C, Kumar KMD. Economic cost of diabetes care the bangalore urban district diabetes study. Int J Diab Dev Countries. 1999;19:87-97.

32. Segel JE. Cost-in-Illness Studies - A Primer. RTI International RTI-UNC Center of Excellence in Health Promotion Economics. 2006.

33. Sanchez LA. Pharmacoeconomics: Principles, Methods, and Application. In: Dipiro JT, Talbert RL, Yee GC, Matzke GR, Wells BG, Posey LM, et al, editors. Pharmacotherapy a pathophysiologic approach. 7th ed. New York (NY): McGrawHill Medical; 2008. p. 1-14.

Cite this article as: Prajapati A, Kothari N, Ganguly B. Economic burden of diabetes mellitus in western India - a hospital based study. Int J Basic Clin Pharmacol 2016;5:2572-80. 